\title{
Effect of modified atmosphere packaging on the quality and bioactive compounds of Chinese cabbage (Brasicca rapa L. ssp. chinensis)
}

\author{
Bevly Mmakatane Mampholo, ${ }^{a}$ Dharini Sivakumar, ${ }^{{ }^{*}}$ Mervyn Beukes $^{b}$ \\ and Willem Jansen van Rensburg ${ }^{\mathrm{c}}$
}

\begin{abstract}
${ }^{\text {a }}$ Postharvest Technology Group, Department of Crop Sciences, Tshwane University of Technology, Pretoria West Campus, South Africa

${ }^{\mathrm{b}}$ Department of Biochemistry, University of Pretoria, Pretoria, South Africa

${ }^{\mathrm{c}}$ Agricultural Research Council, Vegetable and Ornamental Plant Institute, Pretoria, South Africa

* Correspondence to: Dharini Sivakumar, Postharvest Technology Group, Department of Crop Sciences, Tshwane University of Technology, Pretoria West Campus, South Africa; Email: dharinisivakumar@yahoo.co.uk; SivakumarD@tut.ac.za
\end{abstract}

\begin{abstract}
BACKGROUND: The perishability of Brassica chinensis poses a major challenge to distribution and marketing. The aim of this work was to select a suitable modified atmosphere packaging to retain the overall quality and bioactive compounds during storage.

RESULTS: Four types of biorientated polypropylene packaging (BOPP) - BOPP03, BOPP04, BOPP05 and BOPP06 - with different perforations were evaluated regarding the maintenance of quality parameters (weight loss, leaf yellowing, colour $L^{*}, C^{*}, h^{\circ}$ ), decay, chlorophyll a, chlorophyll b, bioactive compounds (carotenoids, ascorbic acid, total phenolic compounds), antioxidant scavenging activity, overall appearance and odour evaluation, at $10^{\circ} \mathrm{C}$ at 2, 4, 6, 8 and 10 days. Leaves were packed in BOPP (two 2-mm holes) and packed and unpacked leaves were included for comparison. The modified atmosphere created $(2 \%$ $\mathrm{O}_{2}$ and $7 \% \mathrm{CO}_{2}$ ) inside the BOPP05 reduced leaf yellowing (higher $h^{\circ}$ ), improved the overall appearance with acceptable odour, moderately maintained chlorophyll $a$ and $b$, bioactive compounds and antioxidant scavenging activity, and remained marketable for up to 10 days at $10^{\circ} \mathrm{C}$. Gas composition within the packages influenced the retention of bioactive compounds and overall quality.
\end{abstract}

CONCLUSION: Application of BOPP05 is a promising method for extending the shelf life of $B$. chinensis leaves in order to promote its utilisation and commercialisation via urban fresh-produce markets.

Keywords: leafy vegetables; overall quality; total phenols; antioxidant scavenging activity; marketability; shelf life 


\section{INTRODUCTION}

Brasicca rapa L. ssp. chinensis is a variety of Chinese cabbage which belongs to the family Cruciferae. It is an important leafy vegetable that is cultivated in the Far East and South-East Asia.[1] It is also known as an exotic leafy vegetable in the UK and USA.[2] In South Africa, B. chinensis is a popular leafy vegetable among the local community because it is easy to cultivate with minimal management and is the cheapest leafy vegetable with the most readily available source of nutritional compounds and fibre. It is served as a side dish in cooked form with a thick starchy maize meal. It is known as a non-heading type of Chinese cabbage,[3] but it produces clusters of dark green leaves on short light green to white petioles. $B$. chinensis contains $1020 \mathrm{~g} \mathrm{Ca} \mathrm{kg}^{-1} \mathrm{FW}, 26 \mathrm{~g} \mathrm{Fe} \mathrm{kg}^{-1} \mathrm{FW}, 2305 \times 10^{-5} \mathrm{~g} \beta$-carotene $\mathrm{kg}^{-1}$ FW,[3] and $10.926 \mu \mathrm{mol} \mathrm{g}^{-1} \mathrm{DW}$ total glucosinolates.[4] The breakdown products of glucosinolates in $B$. chinensis are reported to reduce the risk of cancer.[4]

On the other hand, Brassica vegetables also contain high contents of bioactive compounds including ascorbic acid and polyphenols contributing towards positive health benefits due to their strong antioxidant capacity.[5] Phenolic compounds are secondary metabolites that play a major role in the prevention of cancer and cardiovascular diseases.[6] Flavonoids are ployphenolic compounds that can act as antioxidants and B. chinensis contains flavonols (kempferol) ranging from 0.2002 to $0.25 \mathrm{~g} \mathrm{~kg}^{-1}$ edible portion.[7] Therefore, the nutritional status of $B$. chinensis, and its ability to grow quickly and become harvestable within a short period make it a potentially suitable crop for inclusion in sustaining nutrition-intervention programmes aimed at combating hidden hunger among rural Africans.[8]

At present the fresh leaves are subjected to solar drying.[9] Complete drying could produce caramelised and crusted pieces.[9] Direct exposure to solar radiation destroys colour, vitamins and flavour.[9] On the other hand, after harvest, the leafy vegetables are prone to severe moisture loss due to their high ratio for the surface area to volume. This results in a series of physical and biochemical changes that cause loss of fresh weight, nutritional value (especially ascorbic acid), texture (shrivelling), colour (yellowing of leaves), flavour, taste, and rotting or spoilage, eventually making the vegetable unattractive and unsaleable.[9] Reducing these losses during harvest and post-harvest chain is an important part of sustainable agricultural development efforts to increase food availability. The application of modified atmosphere packaging (MAP) technology will be beneficial in reducing the loss of quality and quantity.[10] The bioactive compounds might be lost due to inappropriate storage conditions during marketing prior to consumption. Hence, it is necessary to investigate the influence of different modified atmosphere conditions at $10^{\circ} \mathrm{C}$ on bioactive compounds as well as on overall quality in order to make recommendations to the retailers marketing Chinese cabbage.

Therefore, this study aims to investigate the effect of different modified atmospheres created inside packages made from biorientated polypropylene - BOPP03, BOPP04, BOPP05 and BOPP06 - on quality parameters and bioactive compounds of Chinese cabbage (B. chinensis) during storage at $10^{\circ} \mathrm{C}$ from 2 to 10 days. 


\section{EXPERIMENTAL}

\section{Growth and harvesting of Brassica chinesis}

B. chinensis plants were grown at the Experimental Station, Agriculture Research Council Vegetable and Ornamental Plant Institute, Roodeplaat, under open-field conditions during winter day temperatures of $10^{\circ} \mathrm{C}$, and night temperatures of $1{ }^{\circ} \mathrm{C}$. Leaf growth was monitored throughout the growing period and the medium-sized leaves (marketable stage) were harvested during the early morning for this trial. Leaves were harvested from 60 plants and one leaf weighed $28 \mathrm{~g}$. After harvesting, the leaves were packed in an upright position in clean plastic crates and transported to the Tshwane University of Technology, Experimental Farm Cold Storage Facility at $10^{\circ} \mathrm{C}$ within $45 \mathrm{~min}$.

\section{Modified atmosphere packaging and storage}

Approximately $232 \mathrm{~g}$ leaves of $B$. chinensis were packed separately in four types of biorientated polypropylene packages with different perforations obtained from Knilam Packaging (Pty) Ltd (Cape Town, South Africa). The thickness of the bags was $35 \mu \mathrm{m}$ (size $40 \mathrm{~cm} \times 18 \mathrm{~cm}$ ), and sealed with a heat sealer in order to create suitable internal atmospheres. Laser perforation technology was adopted to perforate (micro-perforation) the base of the three films having $\mathrm{O}_{2}$ permeances between $24 \times 10^{-14}$ and $38 \times 10^{-14} \mathrm{~mol} \mathrm{~s}^{-1} \mathrm{~m}^{-2} \mathrm{~Pa}^{-1}$; and water vapour transmission rate of $11.8 \times 10^{-11} \mathrm{~mol} \mathrm{~s}^{-1} \mathrm{~m}^{-2} \mathrm{~Pa}^{-1}$ at $23^{\circ} \mathrm{C}$ and the proportion of material perforated was $0.008 \%, 0.001 \%$ and $0.09 \%$ respectively, for BOPP05, BOPP06 and BOPP04. The BOPP03 packaging was not perforated (according to the supplier).

The unpacked leaves and BOPP packaging perforated with two 2-mm holes at the bottom (macro-perforation) were included for comparisons. All treatments, including leaves packed in the BOPP - BOPP03, BOPP04, BOPP05, BOPP06 - and the unpacked leaves were stored at $10^{\circ} \mathrm{C}, 80 \% \mathrm{RH}$ for 10 days. The storage temperatures chosen for this study are representative of the retail display market conditions in South Africa. Each treatment had six replicates, each containing $232 \mathrm{~g}$ of leaves. Head-space gases $\mathrm{CO}_{2}$ and $\mathrm{O}_{2}$ were measured using a PBI Dansensor $\mathrm{CO}_{2} / \mathrm{O}_{2}$ gas analyser (Checkmate 9900; Dansensor, Ringsted, Denmark) after removal from cold storage at designated storage intervals. Gas samples were analysed from three replicates of each kind of MAP containing the leaves of $B$. chinensis. The RH in the packages was measured at the end of the cold storage period with a hygrometer (HD 8501; Hanna Instruments, Padova, Italy). Leaf samples were removed after $2,4,6,8$ and 10 days and the changes with respect to quality and bioactive compounds in the leaves were investigated.

\section{Quality analysis of leafy vegetable}

The $B$. chinensis leaves subjected to all the treatments mentioned above in this study were weighed before and after 2, 4, 6, 8 and 10 days storage and data expressed as percentage weight loss. The degree of yellowing for each leaf was determined subjectively by three persons and scored on a scale of 1 to $5(1=$ dark green, $2=$ light green, $3=$ yellowish-green, $4=$ greenish-yellow, $5=$ yellow).[11] Post-harvest decay was assessed on a scale of 1 to 5 $(1=$ no decay, $2=25 \%, 3=50 \%, 4=75 \%$ of the leaf surface affected, and $5=$ entire leaf decayed). Leaf colour was objectively measured with a Minolta CR-400 chromameter (Minolta, Osaka, Japan). The chromameter was calibrated with a standard white tile. In the CIE colour system, positive $a^{*}$ values describe the intensity of red colour, positive $b^{*}$ values 
describe the intensity of yellow colour and the $L^{*}$ value describes lightness (black $=0$, white $=100)$. The colour changes were quantified in the $L^{*}, a^{*}$ and $b^{*}$ colour space. Hue angle $\left[\left(h^{\circ}=180+\tan ^{-1}\left(b^{*} / a^{*}\right)\right]\right.$ and chroma values $\left[C=\left(a^{* 2}+b^{* 2}\right)^{1 / 2}\right]$ were calculated from $a^{*}$ and $b^{*}$ values. The $C^{*}$ represents colour saturation, which varies from dull (low value) to vivid (high value); and the $h^{\circ}$ value is defined as a colour wheel, with red-purple at an angle of $0^{\circ}$, yellow at $90^{\circ}$, bluish-green at $180^{\circ}$ and blue at $270^{\circ}$. Three measurements were taken per leaf, to the right and the left of the main vein (lower region) and closer to the tip of the leaf surface. Ascorbic acid content (AA) was determined from 10 replicate leaves per treatment.

\section{Content of chlorophyll and carotenoids}

Chlorophyll a (Chl a) and chlorophyll $\mathrm{b}(\mathrm{Chl} \mathrm{b})$ were determined according to Wellburn.[12] The freeze-dried leaf sample powder $50 \mathrm{mg}$ (three replicate samples per treatment) was mixed with $5 \mathrm{~mL}$ methanol $\left(96 \mathrm{~mL} 100 \mathrm{~mL}^{-1}\right)$ and extracted for $2 \mathrm{~h}$. Thereafter, the sample mixture was centrifuged for $10 \mathrm{~min}$ at $4^{\circ} \mathrm{C}(9558 \times \mathrm{g})$. A portion of the supernatant was measured at 470, 646 and $662 \mathrm{~nm}$ (Biochrom Anthos Zenyth 200 Microplate Reader; SMM Instruments, Biochrom Ltd, Johannesburg, South Africa) in order to determine the carotenoid, $\mathrm{Chl} \mathrm{a}$, and $\mathrm{Chl} \mathrm{b}$ contents respectively. The $\mathrm{Chl}$ a and $\mathrm{Chl} \mathrm{b}$ contents were determined according to equations: $\mathrm{Chl} \mathrm{a}=15.65 A_{662}-7.340 A_{646}, \mathrm{Chl} \mathrm{b}=27.05 A_{646}-$ $11.21 A_{662}$, total caretonoids $=\left(1000 A_{470}-2.270 \mathrm{Chl} \mathrm{a}-81.4 \mathrm{Chl} \mathrm{b}\right) / 227$.

\section{Changes in electrolyte leakage}

Electrolyte leakage was determined according to $\mathrm{Lu}[13]$ on 10 leaf discs (50 mm diameter) cut with the aid of a cork borer. The leaf discs were agitated at $20^{\circ} \mathrm{C}$ for $1 \mathrm{~h}$ in $20 \mathrm{~mL}$ of distilled water. The electrolyte leakage (increased conductivity) was measured in $\left(\mathrm{mS} \mathrm{cm}^{-1}\right)$ of the solution. Thereafter, the leaf discs were boiled for $20 \mathrm{~min}$ and allowed to cool to $25^{\circ} \mathrm{C}$ and the total conductivity measurement was recorded. The electrolyte leakage was reported as the percentage of the total conductivity leaked per hour.

\section{Content of total phenols and ascorbic acid}

Total phenolic content (TPC) of the B. chinensis leaves was determined using the FolinCiocalteu assay[14] with some modifications. Total phenols were extracted from $400 \mathrm{mg}$ of freeze-dried samples using $10 \mathrm{~mL}$ of acetone (aqueous solution of $80 \mathrm{~mL}$ in $100 \mathrm{~mL} \mathrm{v} / \mathrm{v}$ ). The sample mixture was then vortexed in the dark for $2 \mathrm{~h}$. After extraction the sample were centrifuged at $11000 \times \mathrm{g}$ for $1 \mathrm{~min}$. A $9 \mu \mathrm{L}$ aliquot of the extract was added to $0.3 \mathrm{~mL}$ of Folin-Ciocalteu reagent followed by addition of $7.5 \mathrm{~g} 100 \mathrm{~mL}^{-1}$ of $\mathrm{Na}_{2} \mathrm{CO}_{3}$ solution. Thereafter, the mixture was vortexed and allowed to stand for $5 \mathrm{~min}$ at $50^{\circ} \mathrm{C}$ for colour development. After $5 \mathrm{~min}$ the mixture was allowed to cool to $25^{\circ} \mathrm{C}$ and the absorbance was read at $760 \mathrm{~nm}$ using a multiplate reader (Biochrom Anthos Zenyth 200 Microplate Reader). Total phenolic compounds were calculated using a standard curve based upon gallic acid and expressed as $\mathrm{mg}$ of gallic acid equivalents (GAE) $\mathrm{g} \mathrm{kg}^{-1} \mathrm{DW}$. AA content was determined from $30 \mathrm{~g}$ leaf using the 2,6-dichlorophenolindophenol titrimetric method. The results were expressed as $\mathrm{g} \mathrm{kg}^{-1} \mathrm{FW} .[15]$ 


\section{Antioxidant activity}

Antioxidant activity was measured using the diphenylpicrylhydrazyl (DPPH; Sigma-Aldrich, Johannesburg, South Africa) scavenging assay.[16] Aliquots $(100 \mu \mathrm{L})$ of leaf samplemethanol extracts $\left(0.01,0.015,0.02,0.025,0.03,0.035\right.$ and $\left.0.045 \mathrm{mg} \mathrm{mL}^{-1}\right)$ were mixed with $10 \mathrm{~mL}$ of $210 \mu \mathrm{L}$ of $0.04 \mathrm{mmol} \mathrm{L}^{-1}$ of DPPH solution. The control samples contained all the reagents except the extract. After vortexing for $1 \mathrm{~min}$, the reaction mixture was allowed to stand in the dark for $60 \mathrm{~min}$ at $25^{\circ} \mathrm{C}$. Thereafter, the absorbance was measured at $515 \mathrm{~nm}$ (Biochrom Anthos Zenyth 200 Microplate Reader). Triplicate measurements were recorded and their percentage inhibition value was calculated according to the equation: scavenging activity $(\%)=\left[\left(A_{\mathrm{c}}-A_{\mathrm{s}}\right) / A_{\mathrm{c}}\right] \times 100$, where $A_{\mathrm{c}}$ and $A_{\mathrm{s}}$ is the absorbance of the control and sample, respectively.

\section{Overall appearance and odour evaluation}

Overall acceptance and odour evaluation was carried out by 16 untrained panellists between 20 and 65 years of age (60\% women and $40 \%$ men). The panellists were asked to assess the overall acceptance of the fresh product at each storage interval after opening the bags. The leaves were individually scored according to a structured hedonic scale from 1 to 10 (10-9 excellent, no defects; 8-7 good; 6-5 fair, with acceptable marketability; 4-3 poor; 2-1 inedible). In the case of odour, the following hedonic scales were used for evaluation: 10-9 typical odour; 8-7 slight off-odour; 6-5 moderate off-odour; 4-3 strong off-odour; 2-1 odour of fermentation. $B$. chinensis leaves that showed scores less than 5 were classified as unmarketable, whereas leaves that showed scores over 5 were classified as marketable.

\section{Statistical analysis}

The experiment was a completely randomised design with different numbers of samples (replications) for different variables and the experiment was repeated twice in order to confirm the observations. The treatment design was a $6 \times 5$ factorial with six factors for postharvest treatments or packaging (Control, BOPP, BOPP03, BOPPP04, BOPP05 and BOPP06) and five storage periods (2, 4, 6, 8 and 10 days). All variables measured were subjected to a two-way analysis of variance (ANOVA). Means of significant effects were separated using Fisher's protected $t$-LSD (least significant differences) at a 5\% significance level. Data were analysed using the statistical programme Genstat for Windows 13th edition, 2010 (Adept Scientific plc, Amor Way, Letchworth, Herts, UK).

\section{RESULTS AND DISCUSSION}

\section{Gas composition within the modified atmosphere packaging, weight loss and visual quality}

Analysis of the gas composition within the packages revealed different gas composition with respect to different types of MAP at equilibrium steady-state [BOPP03 $\left(0.3 \% \mathrm{O}_{2}\right.$ and $25 \%$ $\left.\mathrm{CO}_{2}\right)$; BOPP04 (18\% $\mathrm{O}_{2}$ and 3\% $\left.\mathrm{CO}_{2}\right)$; BOPP05 $\left(2 \% \mathrm{O}_{2}\right.$ and $\left.7 \% \mathrm{CO}_{2}\right)$; BOPP06 $\left(5 \% \mathrm{O}_{2}\right.$ and $\left.\left.15 \% \mathrm{CO}_{2}\right)\right]$. The gas composition within the BOPP was similar to the gas atmospheric gas composition $\left(20.9 \% \mathrm{O}_{2}\right.$ and $0.031 \% \mathrm{CO}_{2}$ ) (Fig. 1A and B). The BOPP03, BOPP04, BOPP05 and BOPP06 contributed significantly $(P<0.05)$ to the reduction in weight loss of $B$. 
chinensis leaves, but no significant difference $(P>0.05)$ was observed between the different types of MAP (no data shown). In this investigation the percentage weight loss significantly $(P<0.05)$ increased for BOPP $(2 \mathrm{~mm}$, two holes $)$ packed and unpacked $B$. chinensis leaves at $10^{\circ} \mathrm{C}$ with storage time. However, unpacked leaves showed the highest percentage of weight loss. Most of the weight loss can be attributed to water loss, and it has been reported that 8690\% of the total weight loss in broccoli (another Brassica vegetable) was due to loss of water.[17]
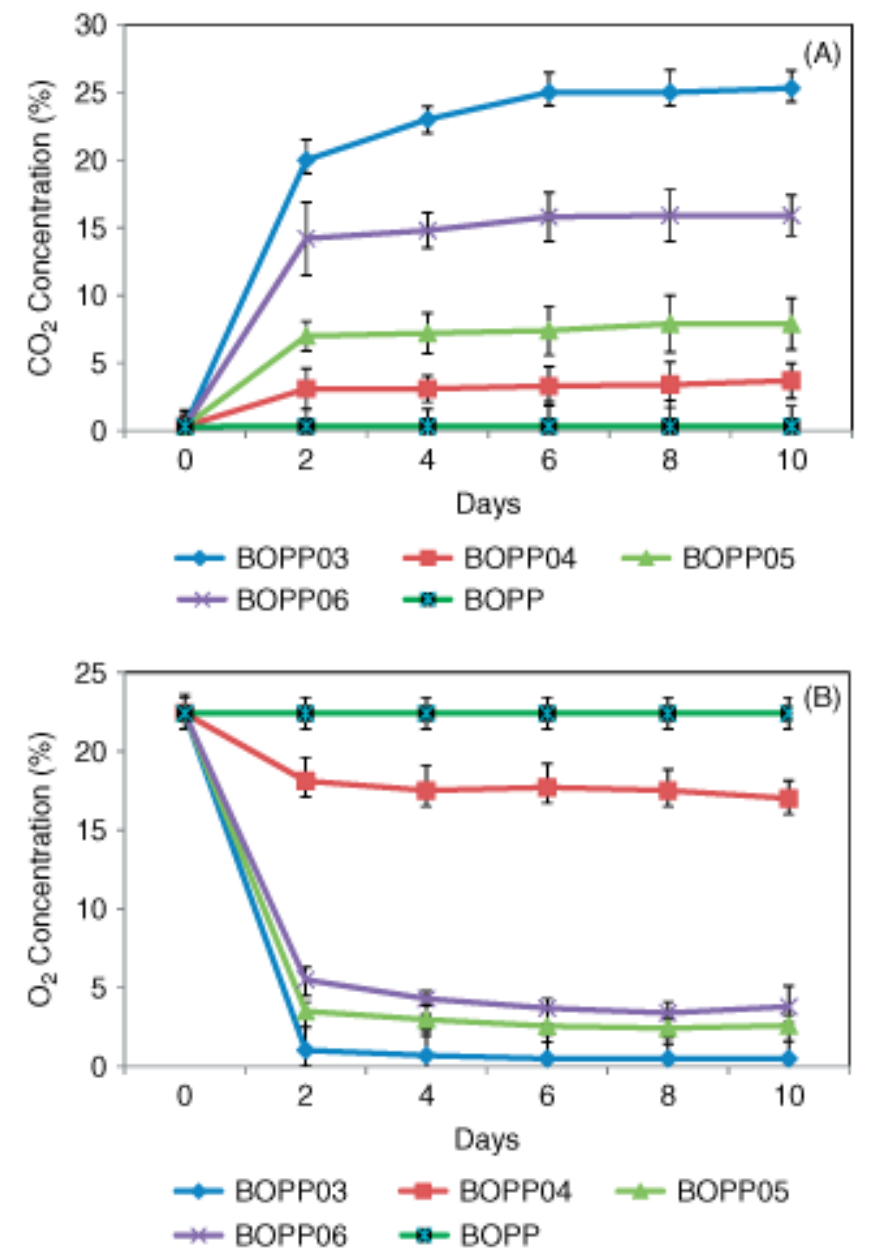

Figure 1. (A) $\mathrm{O}_{2}$ and (B) $\mathrm{CO}_{2}$ composition within the different types of modified atmosphere packaging under storage at $10^{\circ} \mathrm{C}$. Data are means of three replicates. BOPP packaging was perforated with two 2 -mm holes at the bottom (macro-perforation). Four different types of modified atmosphere packaging (BOPP03, BOPP04, BOPP05 and BOPP06) were used. BOPP, biorientated polyproplylene.

Leaf yellowing was noted on the second day in unpacked control leaves and the severity of the yellowing increased with increasing storage time as shown in Fig. 2A. Leaf yellowing acts as a limiting factor apart from wilting especially with brassicas and it indicates that the product has reached the end of its shelf life.[18] The colour of the product is the major quality parameter that determines consumer acceptance.[11] Reducing the $\mathrm{O}_{2}$ concentration showed a mediating effect on the rate of leaf yellowing by slowing the rate of colour degradation of the green leaves. Leaves packed in BOPP04 showed yellowing on the eighth day and it increased significantly $(P<0.05)$ with storage time, and this could be due to the higher $\mathrm{O}_{2}$ composition with the packaging, at equilibrium steady state. The lower $\mathrm{O}_{2}$ composition within the packaging reduced the rate of yellowing.[18] Although leaf yellowing was noted in BOPP ( $2 \mathrm{~mm}$, two holes) on the eighth day, the severity was higher than the BOPP04 packed 
leaves and lower than the unpacked leaves. The other types of MAP tested in this investigation did not show leaf yellowing with increasing storage time at $10^{\circ} \mathrm{C}$.
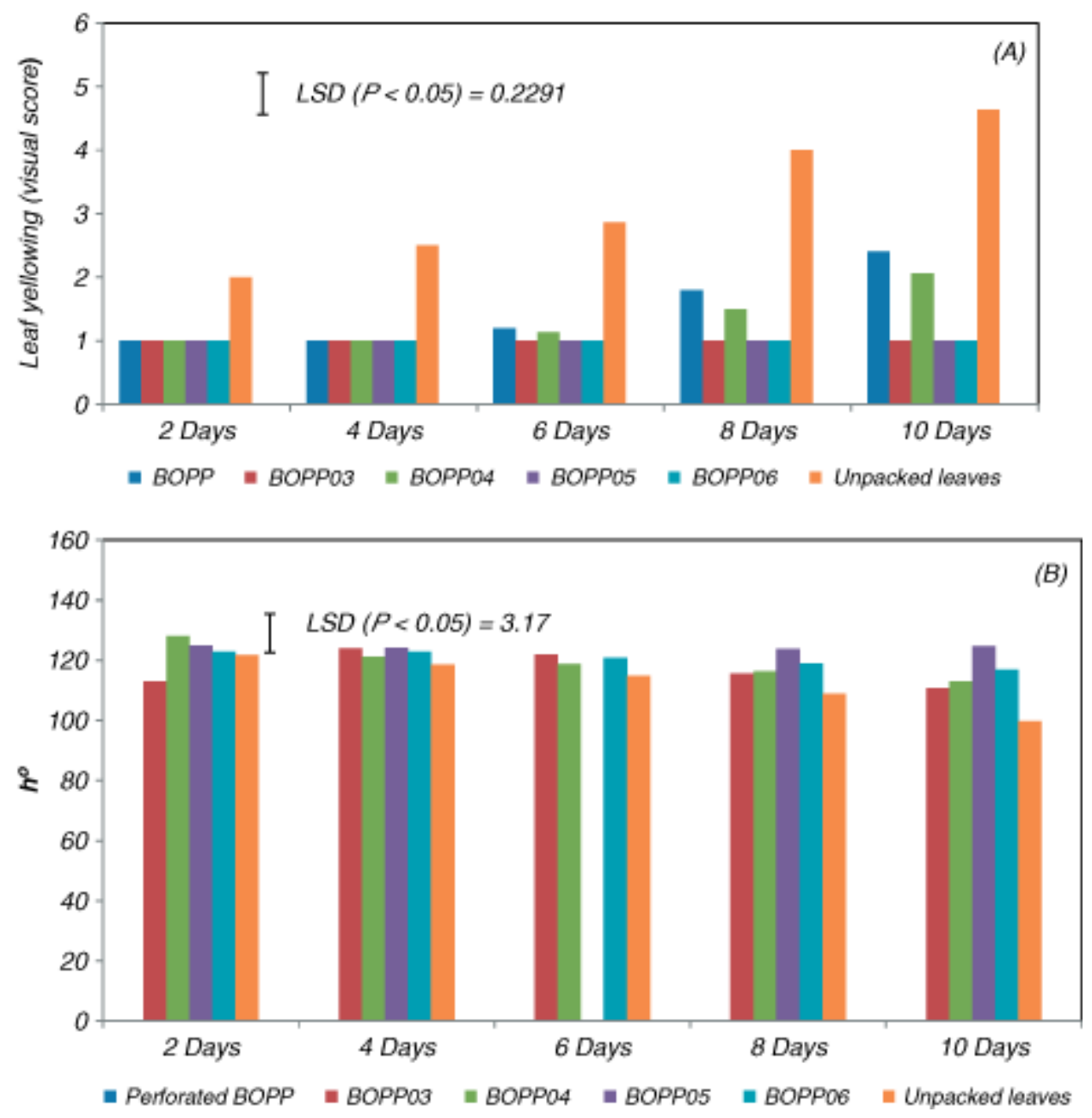

Figure 2. Effect of different types of modified atmosphere packaging (BOPP03, BOPP04, BOPP05 and BOPP06) on (A) leaf yellowing and (B) $h^{\circ}$ in B. chinensis leaves during 2-10 days storage at $10^{\circ} \mathrm{C}$. Data are means of five replicates. BOPP packaging perforated with two 2-mm holes at the bottom (macro-perforation). BOPP, biorientated polyproplylene.

\section{Colour analysis}

Colour parameters $L^{*}$ and $C$ increased while $h^{\circ}$ decreased significantly $(P<0.05)$ in the unpacked leaves with storage time. Storage time showed a significant effect on $L^{*}, C$ and $h^{\circ}$ in this trial with respect to different types of MAP. The $h^{\circ}$ value can be used as an objective form of measurement that can show the small changes in colour.[18] A lower $h^{\circ}$ value results in an increase of leaf yellowing. The different types of MAP and storage time showed significant $(P<0.05)$ interaction on colour $h^{\circ}$ (Fig. 2B). Among the MAP treatments tested, the effect of BOPP04 on colour value $h^{\circ}$ was significantly $(P<0.05)$ higher with storage time. According to our observations, B. chinensis stored in BOPP05 maintained the green colour during storage at $10^{\circ} \mathrm{C}$ for up to 10 days while the unpacked leaves, with a decrease in $h^{\circ}$ value, showed a progressive yellowing as the storage proceeded. Leaves packed in BOPP ( $2 \mathrm{~mm}$, two holes) showed a lower $h^{\circ}$ value from the eighth day onwards. However, the perforated BOPP ( $2 \mathrm{~mm}$, two holes) slightly delayed the decrease of $h^{\circ}$ value when compared with the unpacked leaves. MAP with the lower $\mathrm{O}_{2}$ composition $(\sim 2 \%)$ was effective in 
delaying the loss of the green colour.[18] Leaves in the BOPP03 became soft and olive green in colour on the eighth day. The elevated $\mathrm{CO}_{2}$ concentration and lower $\mathrm{O}_{2}$ concentration observed in the BOPP03 could have induced cytoplasm acidification and affected the mitochondrial function, which could have resulted in oxidative damage in leaf tissue.[19]

\section{Content of chlorophyll a, chlorophyll b and carotenoids}

Chlorophyll is considered to be responsible for the green colour and changes in the chlorophyll content can act as a good index of leaf senescence during storage. The freshly harvested B. chinensis leaves contained $0.03556 \mathrm{~g} \mathrm{~kg}^{-1} \mathrm{DW} \mathrm{Chl} \mathrm{a,} 0.01368 \mathrm{~g} \mathrm{~kg}^{-1} \mathrm{DW} \mathrm{Chl} \mathrm{b}$ and $0.0035 \mathrm{~g} \mathrm{~kg}^{-1} \mathrm{DW}$ carotenoid. The loss of $\mathrm{Chl} \mathrm{a,} \mathrm{Chl} \mathrm{b}$ and carotenoid contents was significantly $(P<0.05)$ higher in unpacked leaves during storage at $10^{\circ} \mathrm{C}$ (Fig. $\left.3 \mathrm{~A}-\mathrm{C}\right)$. The degradation of chlorophyll is due to the chlorophyllase enzyme, which mediates conversion to pheophytin a and pheophytin $b$, respectively.[20,21] Chlorophyll decomposition is linked to senescence and peroxidation of the cell membranes.[22, 23] However, the BOPP05 resulted in a substantial retention of chlorophyll and carotenoid content of $B$. chinensis. The low level of package $\mathrm{O}_{2}$ composition played a major role in maintaining the chlorophyll and carotenoid content in the BOPP05 packed leaves significantly $(P<0.05)$ when compared to the other MAPs tested in this study.
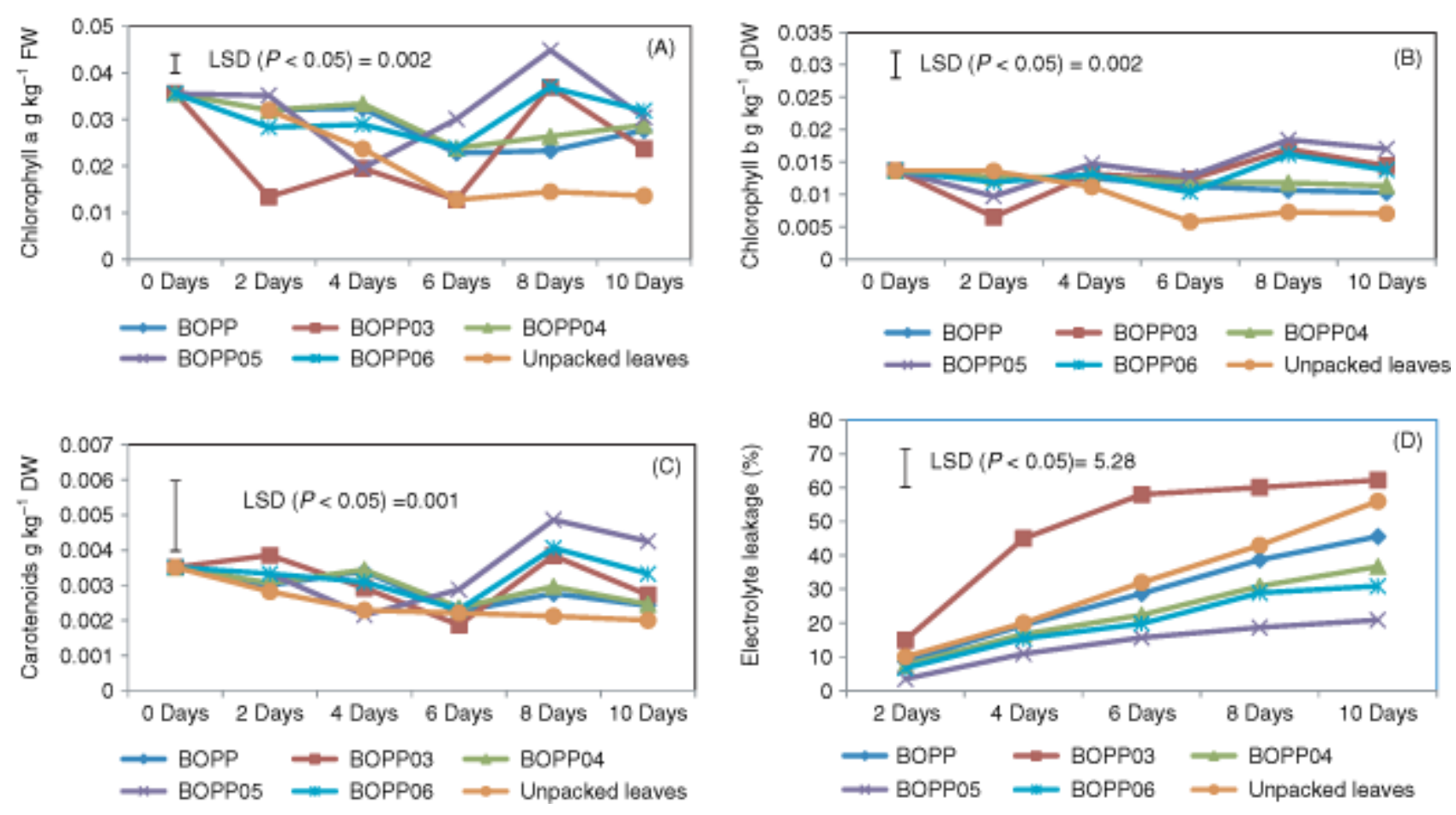

Figure 3. Changes in (A) chlorophyll a, (B) chlorophyll b, (C) carotenoid contents, and (D) percentage leakage in $B$. chinensis leaves packed in four different types of modified atmosphere packaging (BOPP03, BOPP04, BOPP05 and BOPP06) during 2-10 days storage at $10^{\circ} \mathrm{C}$. Data are means of five replicates. BOPP packaging perforated with two 2-mm holes at the bottom (macro-perforation). BOPP, biorientated polyproplylene.

It is evident from this investigation that the maintenance of chlorophyll and carotenoid contents mainly depended on the steady state in package gas composition attained in different MAPs. Similar observations were reported in fresh cut spinach packed in a MAP.[24] In the BOPP04 the higher $\mathrm{O}_{2}$ composition was responsible for the decrease in chlorophyll and carotenoid content. This could be due to the direct effect of $\mathrm{O}_{2}$ on the enzymatic (peroxidase 
activity on cell membrane lipids) degradation activity on chlorophyll pigments.[23, 25] Higher $\mathrm{CO}_{2}$ and lower $\mathrm{O}_{2}$ composition within the packaging affected the chlorophyll and carotenoid contents in the BOPP03. A similar trend was observed in the BOPP06. Leaves packed in the BOPP03 showed $\mathrm{CO}_{2}$ injuries on the tenth day, as shown by the changes in $h^{\circ}$ in Fig. 2B, which resulted in a decrease of chlorophyll and carotenoid contents on the tenth day. Although $\mathrm{CO}_{2}$ injury was noted in the BOPP06 packed leaves, the severity of the injury was less than in the BOPP03 packed leaves. A gradual increase in the percentage of electrolyte leakage was observed in B. chinensis leaves packaged in different types of packaging over time (Fig. 3D). The electrolyte leakage is generally considered as an indirect measure of cell membrane damage.[26] The BOPP05 significantly $(P<0.05)$ reduced the percentage of electrolyte leakage in $B$. chinensis leaves in comparison to the other types of packaging. This observation clearly states that the tissue senescence was delayed in BOPP05 packed leaves. According to Fig. 1A and B the BOPP03 treatment showed a rapid increase of $\mathrm{CO}_{2}$ and decrease of $\mathrm{O}_{2}$ and the observed electrolyte leakage was likely to be due to the cell membrane damage caused by low $\mathrm{O}_{2}$ and high $\mathrm{CO}_{2}$ injury. Therefore, the observed decrease of chlorophyll and carotenoid contents in BOPP03 could be linked to cell membrane damage and loss of cell membrane integrity.[27]

\section{Ascorbic acid, total phenols and antioxidant scavenging activity}

The loss of AA content was significantly $(P<0.05)$ higher in the unpacked and BOPP $(2$ $\mathrm{mm}$, two holes) packed leaves with storage time (Fig. 4A). Higher AA retention in broccoli stored in a MAP was reported when compared to unpacked broccoli.[28] In unpacked leaves, the soft leaf tissue would have lost AA rapidly as a result of water loss and exposed AA to oxidation.[29] On the other hand, the cell wall bound enzyme ascobate oxidase, which facilitates oxidation of AA to 1-dehydroascobic acid, might be released as a result of water loss and tissue damage.[30]

Although the application of different types of MAP helped to reduce water loss and retain AA compared to unpacked leaves and BOPP ( $2 \mathrm{~mm}$, two holes) a decrease in AA with storage time was observed in different types of MAP. The higher $\mathrm{CO}_{2}$ and lower $\mathrm{O}_{2}$ concentration within the BOPP03 packaging affected the AA content. Apples, red currents and conference pears also showed higher losses of AA under elevated $\mathrm{CO}_{2}$ atmospheres.[31, 32] Higher $\mathrm{CO}_{2}$ may stimulate the oxidation of $\mathrm{AA}$ probably due to the activation of ascorbate peroxidase.[33] Higher $\mathrm{O}_{2}$ composition was responsible for the loss of AA in the BOPP04 packed leaves. The AA and carotenoids are two common antioxidants identified in vegetables that prevent the degradation of chlorophyll.[34] In this study the BOPP05 significantly $(P<0.05)$ retained the ascorbic acid content from the eighth day onwards.

TPC increased with storage time in unpacked and perforated BOPP packed leaves (Fig. 4B) due to wilting, causing water loss and breaking down of the leaf tissue, $[35,36]$ and accumulation of phenolic content was reported during post-harvest senescence by Leja $e t$ al.[37] The gas composition in the different types of MAP affected the TPC. The BOPP05 showed significant variation in the TPC with storage time; however, in a comparison of the BOPP, BOPP03, BOPP05, BOPP06 films and the unpacked leaves, the variation in the TPC was kept at a minimum in the BOPP05. The TPC was significantly $(P<0.05)$ lower in the BOPP03 treatment throughout the storage in comparison with the other treatments. The BOPP03 film influenced the increase of $\mathrm{CO}_{2}$ composition (25\%) around the leaves and the $\mathrm{CO}_{2}$ injury caused was clearly shown by the changes in $h^{\circ}$ values mentioned in Fig. 2B and the observed electrolyte leakage in Fig. 3D.The higher $\mathrm{O}_{2}$ concentration within BOPP04 
affected the TPC in B. chinensis leaves. Antioxidant capacity or scavenging activity is a desirable attribute for marketing the potential health benefits of fresh fruit and vegetables. Figure 4C shows the effect of different types of MAP and storage time on the antioxidant scavenging activity of $B$. chinensis leaves stored at $10^{\circ} \mathrm{C}$. The in-package gas composition in the different types of MAP and the storage time affected the antioxidant scavenging activity in B. chinensis leaves. Changes in antioxidant scavenging activity were consistent with the depletion in AA and TPC throughout the storage time with respect to the different types of MAP. B. chinensis leaves in the BOPP05 showed the highest antioxidant scavenging activity with the highest TPC and AA on the tenth day of storage. The different types of MAP and storage time showed a significant $(P<0.05)$ effect on the bioactive compounds TPC, AA and antioxidant scavenging activity.
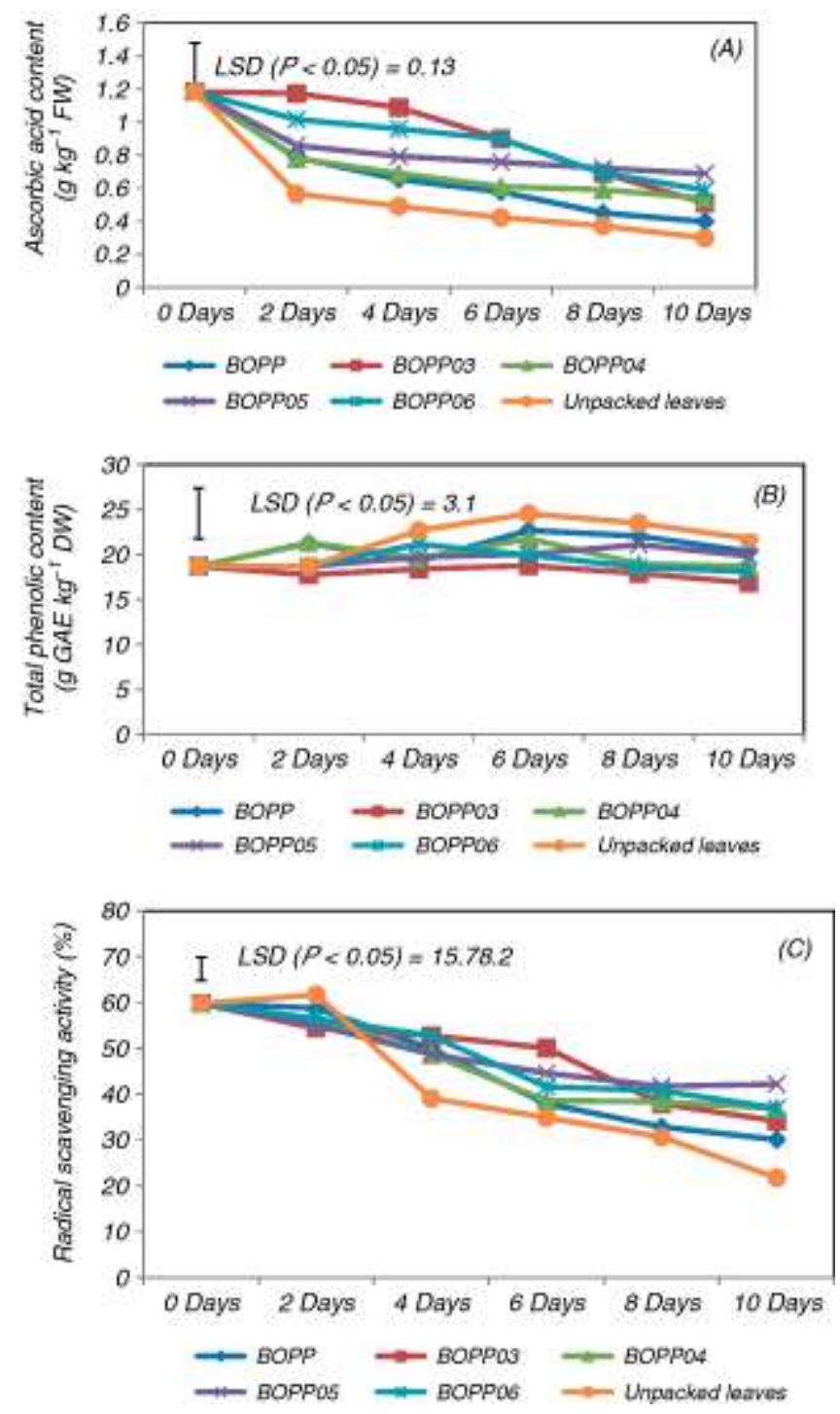

Figure 4. Changes in (A) ascorbic acid content, (B) total phenolic content, and (C) radical scavenging activity in B. chinensis leaves packed in four different types of modified atmosphere packaging (BOPP03, BOPP04, BOPP05 and BOPP06) during 2-10 days storage at $10^{\circ} \mathrm{C}$. Data are means of five replicates. BOPP packaging perforated with two 2-mm holes at the bottom (macro-perforation). BOPP, biorientated polyproplylene. 


\section{Overall acceptance and odour evaluation}

Overall acceptance by the panellists was observed to decrease with the storage time for the leaf samples subjected to different types of MAP. The different types of MAP and storage time significantly $(P<0.05)$ affected the overall acceptance of the $B$. chinensis leaves. Leaves packed in the BOPP05 showed significant $(P<0.05)$ differences when compared to the other treatments, maintaining the overall acceptance throughout the storage (2-10 days) and remaining marketable (Fig. 5). On the other hand the unpacked and BOPP (2 mm, two holes) packed leaves were marketable on the second day at $10^{\circ} \mathrm{C}$. However, on the fourth day the BOPP ( $2 \mathrm{~mm}$, two holes) packed leaves remained marketable but the unpacked leaves became unmarketable. Leaves packed in the BOPP03 and BOPP04 were marketable up to the fourth day while the BOPP06 retained the marketability of the leaves up to the sixth day. On the eighth and the tenth days leaves packed in BOPP05 still remained marketable. The $\mathrm{CO}_{2}$ $(15 \%)$ in the BOPP06 affected the leaf colour due to the $\mathrm{CO}_{2}$ injury after the sixth day. Wilting and leaf yellowing were identified as major factors associated with limiting marketability in the unpacked leaves. Leaf yellowing became a limiting factor for marketability for the BOPP04, while the $\mathrm{CO}_{2}$ injury (brown discolouration) affected the BOPP03 and BOPP06 packed leaves.

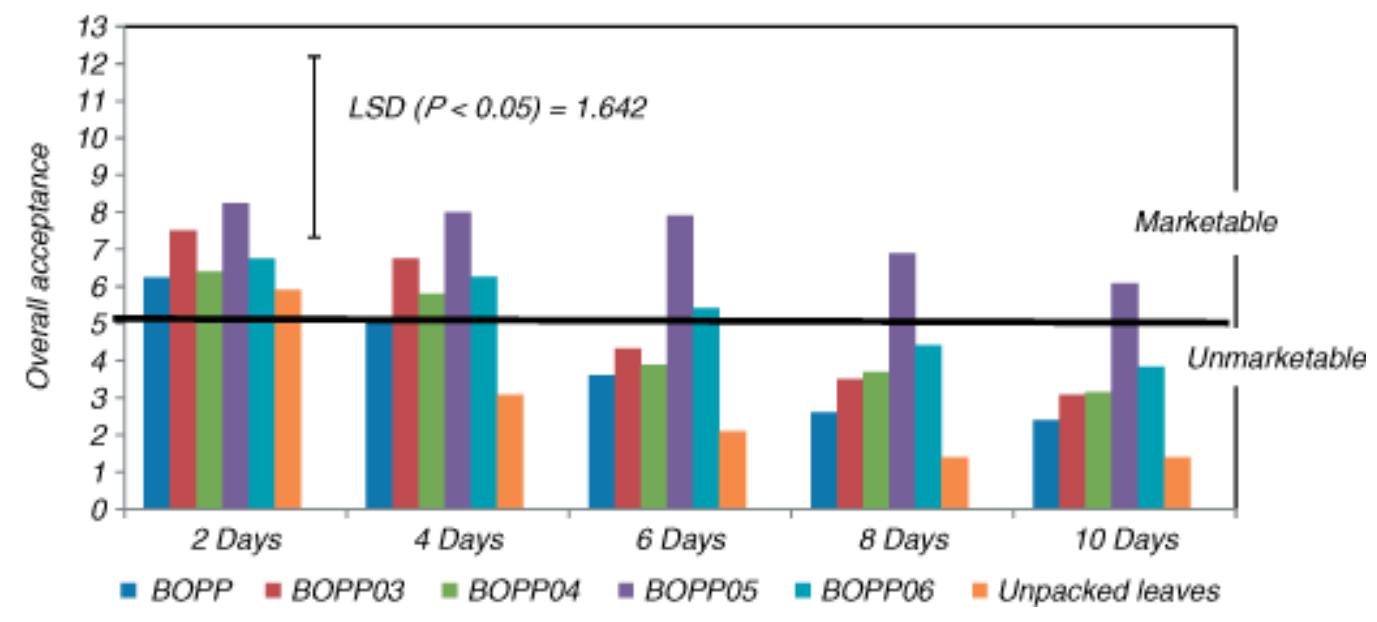

Figure 5. Effect of different types of modified atmosphere packaging (BOPP03, BOPP04, BOPP05 and BOPP06) on (A) overall acceptance of B. chinensis leaves during 2-10 days storage at $10^{\circ} \mathrm{C}$. Data are means of five replicates. BOPP packaging perforated with two 2-mm holes at the bottom (macro-perforation). BOPP, biorientated polyproplylene.

The type of MAP and the storage time significantly $(P<0.05)$ affected the odour of $B$. chinensis leaves. The BOPP05 packed leaves showed acceptable odour (score 8-7) up to the tenth day. Leaf samples in the BOPP03 and BOPP06 showed fermented odour (score 2-1) from the sixth day and eighth day onwards, respectively (data not shown). Under atmospheres $<0.5 \% \mathrm{O}_{2}$ or $>10 \% \mathrm{CO}_{2}$ severe off-odours could develop and affect the shelf life and the marketability of the product.[38-40] The B. chinensis group (pak choi) leaf blades were reported to produce significant amount of methanethiol,[15] a volatile compound that is responsible for the unpleasant odour and its production increased under the anaerobic atmospheres and this could be the reason for the observed unpleasant off-odours noted by the panellists. 


\section{CONCLUSION}

The results obtained from this study provide evidence for the ability of the BOPP05 $\left(2 \% \mathrm{O}_{2}\right.$ and $7 \% \mathrm{CO}_{2}$ ) packaging to minimise post-harvest deterioration and maintain the overall quality of $B$. chinensis leaves at $10^{\circ} \mathrm{C}$ (supermarket shelf temperature). The BOPP05 enabled the retention of the chlorophyll a and b content, ascorbic acid, carotenoids, total phenolic compounds and antioxidant scavenging activity. Application of BOPP05 is a promising method for extending the shelf life of $B$. chinensis leaves in order to promote its utilisation and commercialisation via urban fresh-produce markets.

\section{ACKNOWLEDGEMENTS}

The authors acknowledge the financial support provided by the National Research Foundation (NRF), South Africa. The postgraduate bursary award from the Tshwane University of Technology Research \& Innovation Directorate, Pretoria, South Africa, to Ms Bevly Mmakatane Mampholo is greatly acknowledged.

\section{REFERENCES}

1. Hanson P, Yang R, Chang L, Ledesma L and Ledesma D, Contents of carotenoids, ascorbic acid, minerals and total glucosinolates in leafy brassica pakchoi (Brassica rapa $\mathrm{L}$. chinensis) as affected by season and variety. J Sci Food Agric 89:906-914 (2009).

2. Mahmud TMM, Atherton JG, Wright CJ, Ramlan MF and Ahmad SH, Pak Choi (Brassica rapa ssp. Chinensis L.) quality response to pre-harvest salinity and temperature. J Sci Food Agric 79:1698-1702 (1999).

3. Opena RT, Kuo CG and Yoon JY, Breeding and Seed Production of Chinese Cabbage in the Topics and Subtropics. Technical Bulletin No 17. Asian Vegetable Research and Development Center (AVRDC), Shanshua, Taiwan (1988).

4. Yang J, Zhu Z, Wang Z and Biao Zhu S, Effects of storage temperature on the contents of carotenoids and glucosinolates in pakchoi (Brassica rapa L. ssp. var. Communis). J Food Biochem 34:1186-1204 (2010).

5. Podse ${ }_{3}$ dek A, Natural antioxidants and antioxidant capacity of Brassica vegetables: A review. LWT-Food Sci Technol 40:1-11 (2007).

6. Kroon P and Williamson G, Polyphenols: Dietary components with established benefits to health? J Sci Food Agric 85:1239-1240 (2005).

7. U.S. Department of Agriculture (USDA), Database for the Flavonoid Content of Selected Foods. [Online]. Release 2.1. USDA, Beltsville, MD (2007). Available: http://www.ars.usda.gov/nutrientdata Accessed [21 August 2011]. 
8. Van Averbeke W, Tshikalange TE and Juma KA, The commodity systems of Brassica rapa L. subsp. chinensis and Solanum retroflexum Dun. in Vhembe, Limpopo Province, South Africa. [Online]. Water South Africa, 33: (2007). Available: http://www.wrc.org.za Accessed [12 May 2010].

9. Masarirambi MT, Mavuso V, Songwe VD, Nkambule TP and Mhazo N, Indigenous postharvest handling and processing of traditional vegetables in Swaziland: A review African Journal of Agricultural Research. (AJAR) 5:3333-3341 (2010).

10. Flores FB, Martinez-Madrid MC, Amor MB, Pech JC, Latche A and Romojaro F, Modified atmosphere packaging confers additional chilling tolerance on ethylene inhibited cantaloupe Charentais melon fruit. Eur J Food Res Technol 219:431-435 (2004).

11. Simos AS and Koukounaras A, Quality and postharvest physiology of rocket leaves. Fresh Produce 1:59-65 (2007).

12. Wellburn AR, The spectral determination of chlorophylls a and $b$, as well as total carotenoids, using various solvents with spectrophotometers of different resolution. J Plant Pathol 144:307-313 (1994).

13. Lu S, Effect of packaging on shelf-life of minimally processed Bok Choy (Brassica chinensis L.). LWT-Food Sci Technol 40:460-464 (2007).

14. Prabhu S and Barrett B, Effects of storage and domestic cooking on the quality and nutrient content of African leafy vegetables (Caciatora and Corchorus tridens). J Sci Food Agric 89:1709-1721 (2009).

15. Association of Official Analytical Chemists, Official Methods of Analysis, 16th edition. AOAC, Gaithersburg, MD (2000).

16. Ribeiro SMR, Barbosa LCA, Queiroz JH, Kn “odler M and Schieber A, Phenolic compounds and antioxidant capacity of Brazilian mango (Mangifera indica L.) varieties. Food Chem 110:620-626 (2008).

17. Forney CF and Jordan MA, Anaerobic production of methanethiol and other compounds by Brassica vegetables. HortScience 34:696-699 (1999).

18. O'Hare TJ, Wong LS and Prasad A, Leafy Asian Vegetables: Extending Their Shelf Life. A report for the Rural Industries Research and Development Corporation, Australian Government . RIRDC Publication No 99/159. Canberra, Australia (1996).

19. Tudela JA, Esp1'n JC and Gil MI, Vitamin C retention in fresh-cut potatoes. Postharvest Biol Technol 26:75-84 (2002)

20. López-Ayerra B, Murcia MA and Garcia-Carmona F, Lipid peroxidation and chlorophyll levels in spinach during refrigerated storage and after industrial processing. Food Chem 61:113-118 (1998). 
21. Nisha P, Singhal RS and Pandit AB, A study on the degradation kinetics of visual green colour in spinach (Spinacia oleracea L.) and the effect of salt therein. J Food Eng 64:135142 (2004).

22. Deschene A, Paliyath G, Lougheed EC, Dumbroff EB and Thompson JE, Membrane deterioration during postharvest senescence of broccoli florets: Modulation by temperature and controlled atmosphere storage. Postharvest Biol Technol 1:19-31 (1994).

23. Zhuang H, Hildebrand DF and Barth MM, Senescence of broccoli buds is related to changes in lipid peroxidation. J Agric Food Chem 43:2585-2591 (1995).

24. Kaur P, Rai DR and Paul S, Quality changes in fresh-cut spinach (Spinacia oleracea) under modified atmospheres with perforations. J Food Qual 34:10-18 (2001).

25. Gökmen V, Bahceci KS, Serpen A and Acar J, Study of lipoxygenase and peroxidise as blanching indicator enzymes in peas: change of enzyme activity, ascorbic acid and chlorophylls during frozen storage. LWT-Food Sci Techol 38:903-908 (2005).

26. Hong, JH, Douglas JM, Mary JC and Gross KC, Tomato cultivation systems affect subsequent quality of fresh cut fruit slices. JAmSoc Hort Sci 125:729-735 (2000).

27. Luo y, McEvoy JL, Wachtel MR, Kin JG and Huang Y, Package atmosphere affects postharvest biology and quality of fresh-cut cilantro leaves. HortScience 39:597-570 (2004).

28. Barth MM, Kerbel EL, Perry AK and Schmidt SJ, Modified atmosphere packaging affects ascorbic acid, enzyme activity and market quality of broccoli. J Food Sci 58:140-143 (1993).

29. Nunes MCN, Brecht JK, Morais AMMB and Sargent SA, Controlling temperature and water loss to maintain ascorbic acid levels in strawberries during postharvest handling. $J$ Food Sci 63:1033-1036 (1998).

30. Loewus FA and Loewus MW, Biosynthesis and metabolism of ascorbic acid in plants. CRC Crit Rev Plant Sci 5:101-119 (1987).

31. Bangerth $\mathrm{F}$, The effect of different partial pressures of $\mathrm{CO}_{2}, \mathrm{C}_{2} \mathrm{H}_{4}$, and $\mathrm{O}_{2}$ in the storage atmosphere on the ascorbic acid content of fruits and vegetables. Qual plant Plant Foods Hum Nutr 27:125-133 (1977).

32. Veltman RH, Sanders MG, Persijn ST, Peppelenbos HW and Oosterhaven J, Decreased ascorbic acid levels and brown care development in pears (Pyrus communis L. cv.

Conference). Physiol Plantarum 107:39-45 (1999).

33. Lee SK and Kader AA, Preharvest and postharvest factors influencing vitamin $\mathrm{C}$ content of horticultural crops. Postharvest Biol Technol 20:207-220 (2000).

34. Schwartz S and Vonelbe J, Kinetics of chlorophyll degradation to pyropheophytin in vegetables. J Food Sci 48:1303-1306 (1983). 
35. Oboh G, Effect of blanching on the antioxidant properties of some tropical green leafy vegetables. LWT-Food Sci Technol 38:513-517 (2005).

36. Rivera JRE, Stone MB, Stushnoff C, Pilon-Smits E and Kendall PA, Effects of ascorbic acid applied by two hydrocooling methods on physical and chemical properties of green leaf lettuce stored at 5॰C. J Food Sci 71:270-276 (2006).

37. Leja M, Mareczek A, Starzynska A and Roz S, Antioxidant ability of broccoli flower buds during short-term storage. Food Chem 72:219-222 (2001).

38. Ballantyne A, Stark R and Selman JD, Modified atmosphere packaging of broccoli florets. Int J Food Sci Technol 23:353-360 (1988).

39. Forney $\mathrm{CF}$ and Rij RE, Temperature of broccoli florets at time of packaging influences package atmosphere and quality. HortScience 26:1301-1303 (1991).

40. Kasmir RE, Kader AA and Klaustermeyer A, Influence of aeration rate and atmospheric composition during simulated transit on visual quality and off-odor production by broccoli. HortScience 9:228-229 (1974). 